\section{Disinfection of dental impressions - compliance to accepted standards}

\author{
N. Almortadi ${ }^{1}$ and R. G. Chadwick ${ }^{2}$
}

VERIFIABLE CPD PAPER
IN BRIEF

- Disinfection of dental impressions must be undertaken to prevent transmission of bloodborne viruses to members of the dental team.

- The correct dilution of the disinfection agent should be observed.

- The dentist should indicate clearly to the dental technician that disinfection has been undertaken.

- Repeat disinfection of impressions by technicians risks their dimensional stability.

\begin{abstract}
Introduction The responsibility of ensuring impressions have been cleaned and disinfected before dispatch to the dental laboratory lies solely with the dentist. Uncertainty of impression disinfection risks both the health of the receiving dental technician and potential repeat disinfection of an already disinfected impression with detrimental consequences for its dimensions. Objective To ascertain, from the perspectives of dentists and dental technicians, current impression decontamination and disinfection practices with, in the case of the technicians, an estimate of the relative prevalence of contaminated voids within apparently disinfected impressions. Design Anonymous postal questionnaire. Method Dentist $(n=200)$ and dental technician $(n=200)$ potential participants, selected at random from the registers held by the General Dental Council, were invited to complete an anonymous postal questionnaire that sought to establish current practices and perceived effectiveness of impression disinfection. Results Questionnaire return rates of $42.1 \%$ and $31.2 \%$ were recorded for dentists and dental technicians respectively. A wide range of solutions, at different dilutions of the same product, was used by the dentists to disinfect dental impressions. $37.2 \%$ rinsed the impressions with water, and $2.6 \%$ always brushed debris away, before disinfection. $24.7 \%$ of dentists did not inform the laboratory of disinfection. Irrespective of the disinfection status of the received impressions, 50\% of the responding dental technicians disinfected all impressions. 95\% of them had received blood-contaminated impressions. 15\% had encountered blood-filled voids upon trimming back the peripheries of impressions. 64.7\% were confident that the impressions received by them had been disinfected by the dentists. Conclusions Compliance with good practice is less than ideal and education in impression disinfection for both dentists and dental technicians is required to address this.
\end{abstract}

\section{INTRODUCTION}

The British Dental Association has for some years recommended the decontamination and disinfection of dental impressions ${ }^{1}$ before sending them to the dental laboratory. Current guidance on the decontamination and disinfection of dental impressions is clearly set out in the Advice Sheet A12 produced by that organisation. ${ }^{2}$ This clearly states that 'the responsibility for ensuring impressions

'Lecturer, Department of Applied Dental Sciences, Faculty of Applied Medical Sciences, Jordan University of Science and Technology (JUST), Jordan; ${ }^{2 *}$ Clinical Senior Lecturer in Restorative Dentistry and Honorary Consultant in Restorative Dentistry, The Dental School and Hospital, University of Dundee, Park Place, Dundee, DD1 4HN

*Correspondence to: Dr Graham Chadwick

Email: r.g.chadwick@dundee.ac.uk

\section{Refereed Pape}

Accepted 28 July 2010

DOI: $10.1038 /$ sj.bdj.2010.1134

${ }^{\circledR}$ British Dental Journal 2010; 209: 607-611 have been cleaned and disinfected before dispatch to the laboratory lies solely with the dentist. It is good practice to agree the cleaning and disinfection process with the laboratory and label the device to indicate disinfected status'. In addition, they point out that uncertainty of disinfection risks repeated disinfection of an impression in the dental laboratory. This may have detrimental consequences for its dimensions.

Previous investigations of impression disinfection, against this ideal, ${ }^{3,4}$ within the setting of general dental practice, have demonstrated that cross infection control was not routine, with almost 25\% of impressions received by the laboratory being visibly contaminated with blood ${ }^{3}$ and inappropriately disinfected in $43 \%$ of cases. ${ }^{4}$ In light of these findings it is perhaps not surprising that Kugel et al. ${ }^{5}$ found a lack of confidence among dental technicians that impressions were disinfected resulting in repeat disinfection of some impressions. Such doubt has also been noted by others ${ }^{6}$ and the practice of repeat disinfection risks the surface detail and accuracy of the impression. ${ }^{2}$ It is also apparent that in some cases the dentists prescribing the restorations have little knowledge of the practices used by the dental laboratory for, in the study of Pang and Millar,' when asked 'Does your laboratory technician disinfect working impressions before pouring?' most respondents (72\%) were unsure.

To achieve impression disinfection it is generally accepted that different chemical agents may be used. ${ }^{8}$ Clearly these should be applied as recommended by the manufacturer of the product. Within the literature however there is variation in the method of application of such agents (spraying or immersion). ${ }^{7-9}$ As chemical disinfection is a surface phenomenon ${ }^{10}$ the removal of blood and saliva beforehand, by a combination of brush and water rinsing, ${ }^{11-14}$ is 
desirable as rinsing alone does not remove contamination completely. ${ }^{12-14}$ Of the various methods of disinfectant agent application, immersion is considered to be the most reliable ${ }^{15,16}$ because all exposed surfaces of the impression trays and materials are covered by the disinfectant. ${ }^{17-21}$ Such a technique, in comparison to spraying, minimises the risks of incomplete coverage and hazard of disinfectant inhalation by the user. $^{13}$ On the other hand, spraying is considered by some as a suitable disinfection method ${ }^{22}$ that also decreases the chances of impression distortion ${ }^{23}$ that may occur following prolonged immersion. Spraying is however not a preferred method of the British Dental Association ${ }^{24}$ and, in their most recent guidance, they recommend only either immersion or dipping, preferring the latter so as to avoid distortion of hydrocolloid and polyether impression materials. ${ }^{2}$

This study sought to ascertain, from the perspectives of dentists and dental technicians, current impression decontamination and disinfection practices with, in the case of the technicians, an estimate of the relative prevalence of contaminated voids within apparently disinfected impressions.

\section{MATERIALS AND METHODS}

Two postal questionnaires and covering letters were designed according to the principles of Dillman ${ }^{25}$ for postal distribution to both dental technicians and dentists. Before finalisation each was piloted upon convenience samples of the target groups to maximise the clarity of the questionnaire. Once in final form copies were sent to the Scientific Officer of the Research Ethics Service of Fife, Forth Valley and Tayside, with the proposed covering letters, to determine if ethical approval was required. The reply received stated that the work proposed did not require ethical review under the terms of the Governance Arrangement for Research Ethics Committees (GAfREC) in the UK.

The questionnaires were constructed to permit anonymous return and were distributed nationally, within the UK, to 200 registered dental technicians and 200 registered dentists. Potential participants were randomly selected from the electronic registers, held by the General Dental Council in February, 2009, of the professions

Table 1 The names (as stated by the respondents) and, where stated, concentrations of chemicals used to disinfect alginate and silicone impressions by the respondent dentists

\begin{tabular}{|c|c|c|}
\hline Chemical & Number & Concentrations used \\
\hline Sodium hypochlorite ${ }^{1}$ & 8 & $0.001 \%, 8 \%, M R$ \\
\hline Perform² & 65 & $2 \%, M R$ \\
\hline Sterilox ${ }^{3}$ & 10 & $20 \%, 1: 20$ dilution, $\mathrm{MR}, 20 \mathrm{ml} / 100 \mathrm{ml}$ \\
\hline Impressive & 13 & $60-90 \%$, spray, MR \\
\hline Virkon & 5 & $1 \%, M R$ \\
\hline Wright & 2 & - \\
\hline Unoguard & 2 & - \\
\hline Dimenol $^{4}$ & 2 & - \\
\hline Aerosept ${ }^{5}$ & 2 & $2 \%$ \\
\hline Ethanol $^{6}$ & 2 & - \\
\hline Presem Solution & 2 & MR \\
\hline Mictan & 2 & - \\
\hline Durr ${ }^{7}$ & 2 & Ready-mixed \\
\hline Lometos & 2 & $25 \%$ \\
\hline Unident Impression ${ }^{8}$ & 2 & $10 \%$ \\
\hline Presept & 2 & One tablet / Litre, MR \\
\hline Impressive* & 2 & - \\
\hline Impressive Propan-2* & 1 & $60-90 \%$ \\
\hline Eurosept Max Impression* & 1 & MR \\
\hline Virlon* & 1 & - \\
\hline Uno* & 1 & - \\
\hline Impression disinfectant spray* & 1 & - \\
\hline \multicolumn{3}{|c|}{ 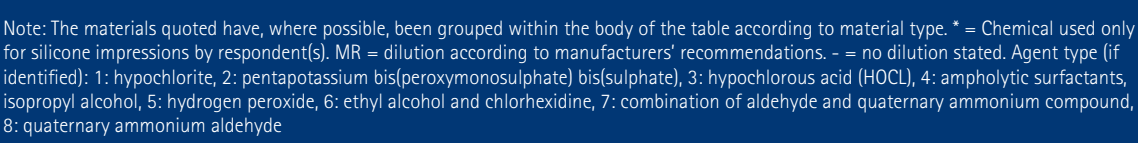 } \\
\hline
\end{tabular}

concerned. Randomisation was achieved by sequentially numbering each entry in the electronic versions of the registers and selecting those whose number coincided with a list of random numbers produced using the random number function in the spreadsheet package Excel (Microsoft Excel 2002, Microsoft Ltd., Reading). An introductory letter and stamped addressed return envelope for the completed questionnaires were included in the mailing. The introductory letter invited the potential participants to take part and stated that non-return of the questionnaire would be indicative of a lack of consent to participate in the study. To ensure maximum confidentiality of all respondents no hidden codes were embedded in any part of the questionnaires and so it was impossible to know who had participated. For this reason it was impossible to send follow-up letters to non-responders.

Both the dentist and dental technician questionnaires sought to establish if, before disinfecting impressions, the responders rinsed or brushed away debris from them. In addition, details of the disinfection regimes (chemicals used, their dilution, mode and duration of application) were also ascertained. The dentists were also asked their main area of practice and if they routinely communicated the disinfection status of impressions to the dental laboratory and whether this practice altered in the case of impressions from known bloodborne virus carrier patients. The dental technicians were asked from which dental disciplines their impressions 
Table 2 The disinfectants used by the

technicians to treat impressions received

by them in the laboratory

Solution

Mikrozoid

Sigasep

Dip in disinfectant bath (2)

Spray with isolate 2000

Perform ID (4)*

Dettol

Spray with universal disinfectant (4)

Iso rapid disinfectant

Phoraid

Impressive

Spray Terninex II viricided

Note: where more than one respondent indicated use of an agent

the number in parentheses indicates the number of respondents.

*Refers to pentapotassium bis(peroxymonosulphate) bis(sulphate)

came and whether or not they routinely, irrespective of disinfection status, disinfected impressions. Satisfaction with the level of impression disinfection information received from the dentists was also sought together with an estimate of the frequency of receipt of blood-contaminated impressions.

A relational database was constructed using the computer program Paradox (Paradox version 3.5, Borland International, CA 95067-001, USA) for input of data from the completed questionnaires and interrogation. Statistical analyses of the responses were undertaken using Prism (Graph Pad Prism, version 4, Graph Pad Software Inc., San Diego, CA 92121, USA) and Excel (Microsoft Excel, 2002, Microsoft Ltd., Reading).

\section{RESULTS}

\section{The dentists' questionnaire}

Of the 200 questionnaires mailed out 83 were returned completed. A further 3 questionnaires were returned by the postal service marked unknown at this address. The return rate was therefore $42.1 \%$.

The majority of respondents worked in general dental practice $(75.9 \%, \mathrm{n}=63)$. The areas of community dentistry (4.8\%, $\mathrm{n}=4)$, hospital $(4.8 \%, \mathrm{n}=4)$, and specialist practice $(6.0 \%, \mathrm{n}=5)$ were represented, though in small number. Eleven respondents stated a specialty (endodontics $(n=1)$,
Table 3 Frequency of blood-contaminated impressions received by the technicians

\begin{tabular}{l|l}
\hline $\begin{array}{l}\text { Frequency of } \\
\text { contamination }\end{array}$ & $\begin{array}{l}\text { Number of } \\
\text { respondents }\end{array}$ \\
\hline Never & 3 \\
\hline Seldom / rarely & 37 \\
\hline Commonly & 16 \\
\hline Frequently & 5
\end{tabular}

Table 4 Frequency of blood-contaminated voids made visible by trimming peripheral extensions of impressions

\begin{tabular}{l|l} 
Frequency & $\begin{array}{l}\text { Number of } \\
\text { respondents }\end{array}$ \\
\hline Never & 20 \\
\hline Seldom / rarely & 25 \\
\hline Commonly & 6 \\
\hline Frequently & 2 \\
\hline
\end{tabular}

implantology $(n=1)$, orthodontics $(n=6)$, prosthodontics $(\mathrm{n}=3)$ ).

Seventy-eight dentists completed the question relating to their disinfection of impressions that were to be cast by a dental laboratory. Of these 74 (94.9\%) always disinfected the impressions, three (3.8\%) sometimes and one (1.3\%) never. Only 29 $(37.2 \%)$ dentists rinsed the impressions with water before disinfection and just two (2.6\%) always brushed away debris. None of the respondents sometimes brushed away debris or stated alternative means of debridement.

A wide variety of chemical solutions and concentrations were used by the dentists to disinfect alginate and silicone impression materials. These responses are summarised in Table 1 . These also indicate, where identification from manufacturer's chemical data sheets was possible, the constituent active chemical disinfection agents within these products. The quoted dilutions are as stated by the respondents.

The majority of dentists immersed their impressions in the disinfectant $(\mathrm{n}=27)$ and some $(n=19)$ sprayed the agent on the surface. The mean time of immersion was 9.18 minutes $(\mathrm{SD}=2.99)$ with a range of 19.5 minutes (minimum $=0.5$ minutes, maximum $=20$ minutes) .

The majority ( $\mathrm{n}=58,75.3 \%$ ) of the respondents informed the dental laboratory that the impressions were disinfected. Nineteen dentists (24.7\%), however, did not.
Twenty-six respondents (31.3\%) advised the dental laboratory of the impressions from patients with bloodborne viruses whereas 51 (61.4\%) did not.

\section{The dental technicians' questionnaire}

A total of 62 questionnaires were returned completed and one by the mail delivery service marked not known at this address. This gave a questionnaire return rate of $31.2 \%$.

The impressions received covered a wide range of dental disciplines (prosthetics ( $n=36)$, crown and bridge $(n=34)$, orthodontics $(n=26)$, periodontology $(n=4)$, paediatric dentistry $(n=3)$ and implantology $(n=24))$.

Upon receipt of the impression $81 \%$ $(\mathrm{n}=47)$ rinsed them with water and 19.0\% $(\mathrm{n}=11)$ did not. 50\% of the respondents $(n=28)$ disinfected the impressions in the dental laboratory and 50\% did not. Table 2 summarises the disinfectants used by the respondents who named these.

$50 \%$ of the respondents $(n=31)$ indicated that if the impression was from a patient with a known bloodborne virus it would be labelled so by the dentist. In this instance $26(46.4 \%)$ of the respondents to this section said they would redisinfect the impressions in the dental laboratory and 30 (53.6\%) would not do so. Table 3 indicates the number of respondents reporting the frequency they received blood-contaminated impressions. 95\% of respondents had encountered this.

Table 4 indicates the frequency of encountering blood-contaminated voids on trimming the peripheral extensions of impressions before casting them. In addition it should be noted that six respondents never trimmed peripheral extensions. 47\% of respondents encountered this rarely and some 15\% encountered such contaminated voids commonly or frequently.

Analyses, by chi-square, of the raw data of the reported frequency of blood contamination of the impressions received and the occurrence of finding bloodfilled voids upon trimming impression peripheries according to specialty of impression origin found no statistically significant effect ( $p>0.05$ ) of specialty upon the reported frequency of blood contamination or the occurrence of blood-filled voids. 
Of those responding 44.1\% ( $\mathrm{n}=15)$ knew if the dentist had disinfected the impressions in all cases and 55.9\% $(n=19)$ did not.

Of those responding 57.1\% $(n=16)$ knew if the dentist had disinfected the impressions in some cases and $42.1 \%(n=9)$ did not.

Of those responding 33\% ( $n=7)$ claimed they did not know how the impressions had been disinfected whereas 66\% $(n=14)$ did.

$64.7 \%(n=22)$ of responders were confident that the impressions were disinfected by the dentist and 35.3\% ( $\mathrm{n}=12)$ were not. The reasons given for not being confident about the disinfection of impressions by the dentist included: some impressions are full of blood; no written communication of this practice received; no verification provided; and impression trays are contaminated with plaster.

\section{DISCUSSION}

The return rates of the questionnaires were $42.1 \%$ for the dentists and $31.2 \%$ for the dental technicians. This is somewhat disappointing, particularly so in the case of the dental technicians. Due to the potentially sensitive nature of the matters disclosed in these no hidden codes, which would permit follow up for non responders, were included. As a result it was not possible to contact those who had not responded. In this way it was hoped that the responses elicited were more likely to be an accurate reflection of current practice. An alternative approach would have been to recruit subjects whose identity was known by means of ethical committee participant information sheets and consent forms. Previous experience ${ }^{26}$ of such an approach, on a less potentially controversial issue (consumer modification of erosive drinks) in the research team where the present project was carried out, suggests strongly that this may well have presented a greater barrier to eliciting a response. The response rate achieved however in the present study could be criticised as biasing the information obtained. Such an issue has been examined previously by Hovland et al. ${ }^{27}$ and shown not to bias the results of dental surveys. It has also been stated there is no agreed standard for the accepted minimum response rate other than that a minimum level of 75\% is considered good. ${ }^{28}$ Low response rates may be due to a lack of time to fill out the questionnaire, no interest in the subject matter or concerns about the confidentiality of the responses. ${ }^{29}$
This last reason is however not a concern in our study as great effort was made to stress confidentiality. The proportion of questionnaires returned by the post office is at a level that agrees with other dental surveys. ${ }^{30}$ Notwithstanding these limitations, the findings of the questionnaires are in some areas disturbing and, despite the disappointingly low return rate, of importance to the dental team. Another view is to argue that the low response rate perhaps reflects a worse trend than reported here as poor disinfection practice may make respondents less likely to respond to the questionnaire.

Current guidance on the decontamination and disinfection of dental impressions is clearly set out in the Advice Sheet A12 produced by the British Dental Association. ${ }^{2}$ This clearly states that 'the responsibility for ensuring impressions have been cleaned and disinfected before dispatch to the laboratory lies solely with the dentist. It is good practice to agree the cleaning and disinfection process with the laboratory and label the device to indicate disinfected status'

They go on to point out that uncertainty of disinfection risks repeated disinfection of an impression in the laboratory. This may have detrimental consequences for its dimensions. Others ${ }^{19}$ have shown that some commercial laboratories routinely disinfect all impressions they receive regardless of whether they have been disinfected by the dentist.

The results of the present work indicate that up to one quarter of the responding dentists do not inform the dental laboratory that the impressions are disinfected and whereas the majority of responders (94.9\%) disinfect impressions, the remainder do not always. Such findings are at odds with the BDA recommendations ${ }^{2}$ and in accord with the earlier findings of others. ${ }^{3-5}$ It would thus appear that in the intervening years, from the initial promotion of such policy ${ }^{1}$ to the present day, ${ }^{2}$ compliance has not improved.

It is also interesting to note that some dentists identified impressions from bloodborne virus carriers to the dental technicians. On the one hand this could be considered laudable and, on the other, unnecessary if a standard cross infection control protocol is being followed. Such a practice offers potential for inappropriate disclosure of personal medical history details if not performed in an anonymised way.

Although many have recommended both rinsing and brushing away debris from an impression before disinfection ${ }^{2,11,13,14,31}$ it is of concern that in the survey of dentists only $37.2 \%$ of respondents rinsed the impressions before disinfection and just two individuals (2.6\%) always brushed away debris. This contrasts with the experience encountered in UK dental hospitals where it is claimed that $100 \%$ of impressions are rinsed. ${ }^{8}$ In the European Union Schools this is reported as 95\%. ${ }^{9}$ It is therefore not surprising that $95 \%$ of the responding technicians had encountered blood-contaminated impressions. The presence of such debris on the surface of the impression will impair the efficacy of the chemical disinfection process ${ }^{32,33}$ which is a surface phenomenon. ${ }^{10}$ In light of this poor communication between dentist and dental laboratory, which has been noted by others previously, ${ }^{5,6}$ it is not surprising that the responding dental technicians were not confident in some cases (35.3\%) that the impressions received were disinfected by the dentist. In the present study the reasons stated for this (no written communication of this practice received, no verification provided) were due to poor dentist to technician communication. The side effect of such poor practice however was for 50\% of the dental technicians to always disinfect the impressions in the dental laboratory upon receipt, irrespective of whether or not this had been carried out previously in the dental surgery. Such repeat disinfection has been reported by others ${ }^{5}$ and risks the surface detail and the accuracy of the impression material. ${ }^{2}$ It is also of interest to note the prevalence of discovering blood-filled voids upon trimming back the peripheral borders of dental impressions as identified by the results of the dental technicians' survey. Some $47 \%$ of respondents encountered this rarely and 15\% encountered this commonly or frequently. It was however not related to a particular clinical specialty. As such voids would not have been in contact with disinfectant, they are a reservoir of potential infection. The prevalence of such voids has not been previously reported in the literature though anecdotally it is often commented upon by dental technicians. It is clear however 
that, upon discovering a void, disinfectant must be applied to protect the dental technicians and prevent the possibility of further contamination. It should be borne in mind however that prolonged disinfection risks deterioration of the impression material. ${ }^{34,35}$

Both the dentists and dental technicians reported the use of a wide variety of disinfectant solutions (Tables 1 and 2). In common with Muller-Bolla et al. ${ }^{9}$ a wide range of immersion times were used that lay within similar ranges of the present work. This range may have been because the concentration of the agents varied but, as is clear from Table 1 , a wide variety of dilutions of the same products was reported by the dentist respondents. This perhaps is suggestive of a degree of confusion surrounding the required concentration and how to practically make up the solution to achieve it. This risks both the effectiveness of the agent ${ }^{36,37,38}$ and the dimensions of the impression ${ }^{39}$ treated with the agent. It is accepted that different agents may be used $^{8}$ but clearly for maximum effectiveness the concentration must be correct.

Most dentists immersed the impressions in the disinfectant solutions whereas, in the present work, some sprayed the impressions. These results agree with the trends found by Muller-Bolla et al. ${ }^{9}$ who reported that $73 \%$ of dentists used immersion to disinfect silicones and 65\% for irreversible hydrocolloids. However these results disagree with Blair and Wassell ${ }^{8}$ who concluded that $23.3 \%$ of dentists used immersion and $83.3 \%$ sprayed. The present survey however did not ask the dental technicians how they applied their disinfectant but this has been found by others to be around 34\% for immersion and 46\% for spraying. 5

It is clear from these results that compliance with good practice is less than ideal and education in impression disinfection of both dentists and dental technicians is required. Better communication between these two groups of professionals would go a long way to improve the situation.
1. British Dental Association. Advice sheet A12: Infection control in dentistry. London, British Dental Association, 2003.

2. British Dental Association. Advice Sheet A12 Infection control in dentistry. London, British Dental Association, 2009

3. Winstanley R B, Carrotte PV, Johnson A. The quality of impressions for crowns and bridges received at commercial dental laboratories. Br Dent J 1997; 183: 209-213.

4. Lynch D, Allen P F. Quality of written prescriptions and master impressions for fixed and removable prosthodontics: a comparative study. Br Dent J 2005; 198: 17-20.

5. Kugel G, Perry R D, Ferrari M, Lalicata P. Disinfection and communication practices: a survey of U.S. dental laboratories. J Am Dent Assoc 2000; 131: 786-792.

6. Sofou A, Larsen T, Fiehn N E, Owall B. Contamination level of alginate impressions arriving at a dental laboratory. Clin Oral Investig 2002; 6: 161-165.

7. Pang $S-K$, Millar B J. Cross infection control of impressions: a questionnaire survey of practice among private dentists in Hong Kong. Hong Kong Dent J 2006; 3: 89-93.

8. Blair F M, Wassell R W. A survey of the methods of disinfection of dental impressions used in dental hospitals in the United Kingdom. Br Dent J 1996; 180: 369-375.

9. Muller-Bolla M, Lupi-Pégurier L, Velly A M, Bolla M. A survey of disinfection of irreversible hydrocolloid and silicone impressions in European Union dental schools: epidemiologic study. Int J Prosthodont 2004; 17: 165-171.

10. Sarma A C, Neiman R. A study on the effect of disinfectant chemicals on physical properties of die stone. Quintessence Int 1990; 21: 53-59.

11. Rowe A H R, Forrest J O. Dental impressions. The probability of contamination and a method of disinfection. Br Dent J 1978; 145: 184-186.

12. Bergman B. Disinfection of prosthodontic impression materials: a literature review. Int J Prosthodont 1989: 2: 537-542.

13. Look J O, Clay D, Gong K, Messer H H. Preliminary results from disinfection of irreversible hydrocolloid impressions. J Prosthet Dent 1990; 63: 701-707.

14. Rios M P, Morgano S M, Stein R S, Rose L. Effects of chemical disinfectant solution on the stability and accuracy of the dental impression complex. J Prosthet Dent 1996; 76: 356-362.

15. Council on Dental Materials, Instruments, and Equipment, Council on Dental Practice, Council on Dental Therapeutics. Infection control recommendations for the dental office and the dental laboratory. J Am Dent Assoc 1988; 116: 241-248.

16. Merchant $V A$. Infection control and prosthodontics. J Calif Dent Assoc 1989; 17: 49-53.

17. ADA Council of Dental Materials and Devices. Revised American Dental Association specification no. 19 for non-aqueous, elastomeric dental impression materials. J Am Dent Assoc 1977; 94: 733-741.

18. Durr D P, Novak E V. Dimensional stability of alginate impressions immersed in disinfecting solutions. ASDC J Dent Child 1987; 54: 45-48.

19. Lepe $X$, Johnson G H, Berg J C. Surface characteristics of polyether and addition silicone impression materials after long-term disinfection. J Prosthet Dent 1995; 74: 181-186.

20. Lepe $X$, Johnson G H. Accuracy of polyether and addition silicone after long-term immersion disinfection. J Prosthet Dent 1997; 78: 245-249.

21. Johnson G H, Chellis K D, Gordon G E, Lepe X.
Dimensional stability and detail reproduction of irreversible hydrocolloid and elastomeric impressions disinfected by immersion. J Prosthet Dent 1998; 79: 446-453.

22. Drennon D G, Johnson $G H$, Powell $G L$. The accuracy and efficacy of disinfection by spray atomization on elastomeric impressions. J Prosthet Dent 1989; 62: 468-475.

23. Wood P R. Cross infection control in dentistry: a practical illustrated guide. London: Wolfe, 1992.

24. British Dental Association, British Dental Trade Association. and Dental Laboratories Association. Disinfection of impressions. BDA News 1995; September (Suppl).

25. Dillman D A. Mail and telephone surveys: the total design method. New York: Wiley, 1978.

26. Syed J. Determination and modification of drink erosive factors. Dundee: University of Dundee, 2007. MDSc Thesis.

27. Hovland E J, Romberg E, Moreland E F. Nonresponse bias to mail survey questionnaires within a professional population. J Dent Educ 1980; 44: 270-274.

28. Bharm J R, Walkom E J, McGettigan P. Response rates and representativeness: a lottery incentive improves physician survey return rates. Pharmacoepidemiol Drug Saf 2005; 14: 571-577.

29. VanGeest J B, Johnson T P, Welch V L Methodologies for improving response rates in surveys of physicians: a systematic review. Eval Health Prof 2007: 30: 303-321.

30. Burke F J T, Wilson N H F, Cheung S W. Glove use by dentists in England and Wales: results of a 2 year follow up survey. Br Dent J 1994; 176: 337-341.

31. Merchant V A, McNeight M K, Ciborowski C J, Molinari J A. Preliminary investigation of a method for disinfection of dental impressions. J Prosthet Dent 1984; 52: 877-879.

32. Dychdala G R. Chlorine and chlorine compounds. In Block S.S (ed). Disinfection, sterilization, and preservation. 4th ed. pp 133-135. Philadelphia: Lea and Febiger, 1991.

33. Martin N, Martin M V, Jedynakiewicz N M. The dimensional stability of dental impression materials following immersion in disinfecting solutions. Dent Mater 2007; 23: 760-768

34. Bergman B, Bergman M, Olsson S. Alginate impression materials, dimensional stability and surface details sharpness following treatment with disinfectant solutions. Swed Dent J 1985; 9: 255-262.

35. Minagi S, Kohada A, Akagawa Y, Tsuru H. Prevention of acquired immunodeficiency syndrome and hepatitis B. Part III: Disinfection of hydrophilic silicone rubber impression materials. J Prosthet Dent 1990; 64: 463-465.

36. Westerholm H S, Bradey D V, Schwartz R S. Efficacy of various spray disinfectants on irreversible hydrocolloid impressions. Int J Prosthodont 1992; 5: $47-54$

37. Beyerle M P, Hensley M, Bradley D V Jr, Schwartz R S, Hilton T J. Immersion disinfection of irreversible hydrocolloid impressions with sodium hypochlorite. Part 1: Microbiology. Int J Prosthodont 1994; 7: 234-238.

38. Memarian M, Fazeli M R, Jamalifar H, Azimnejad A. Disinfection efficiency of irreversible hydrocolloid impressions using different concentrations of sodium hypochlorite: a pilot study. J Contemp Dent Pract 2007; 8: 27-34

39. Vandewalle KS, Charlton D G, Schwartz R S, Reagan S E, Koeppen R G. Immersion disinfection of irreversible hydrocolloid impressions with sodium hypochlorite. Part 2: Effect on gypsum. Int J Prosthodont 1994; 7: 315-322. 